\title{
Harlequin Syndrome post-transsphenoidal pituitary macroadenoma surgery
}

\author{
Gonzalo Díaz-Soto, ${ }^{1}$ Maria J. Vaquerizo, ${ }^{2}$ Ciro García-Álvarez, ${ }^{3}$ Aurelia Villar-Bonet ${ }^{1}$ \\ ${ }^{1}$ Servicio de Endocrinología y Nutrición, Hospital Clínico Universitario, Valladolid, Centro de Investigación de \\ Endocrinología y Nutrición Clínica (IEN), Facultad de Medicina, Valladolid, ${ }^{2}$ Centro de Salud Iscar, Pediatría Atención \\ Primaria Valladolid Este, ${ }^{3}$ Servicio de Oftalmología. Hospital Clínico Universitario, Valladolid, Spain
}

\begin{abstract}
A 45-year-old woman, with a history of asymmetric facial flushing, was presented to the Endocrinology Unit after pituitary macroadenoma removal. After other pathological entities had been ruled out, she was diagnosed with harlequin syndrome following a lesion of the postganglionic sympathetic fibers during transsphenoidal pituitary macroadenoma surgery. We herein report the first case of harlequin syndrome following transsphenoidal pituitary surgery. We describe this difficult and benign diagnosis along with its characteristic imaging.
\end{abstract}

Key words: Neuroendocrinology, Neuroophthalmology, Neurosurgery, Sympathetic skin response

\section{INTRODUCTION}

Harlequin syndrome is defined as asymmetrical facial flushing and sweating with or without ocular signs of Horner's syndrome. ${ }^{1}$ It is a rare, clinically striking disorder and in most cases is of benign nature. It has been associated, inter alia, with brain stem infarcts, superior mediastinal neurinoma, internal jugular vein catheterization and internal carotid artery dissection resulting from damage of the vasodilator sympathetic fibers. ${ }^{2}$

Address for correspondence:

Dr Gonzalo Díaz-Soto, Hospital Clínico Universitario de

Valladolid, Servicio de Endocrinología y Nutrición, C/Ramon y Cajal n 3. 47005 Valladolid, Spain, Tel.: +34 9834200 00,

Ext.: 21615, e-mail: diazsotogonzalo@gmail.com

Received 27-09-11, Revised 03-11-11, Accepted 10-01-12

\section{CASE REPORT}

A 45-year-old woman was presented at the Endocrinology Unit after endonasal transsphenoidal pituitary non-secretory macroadenoma removal (Figure 1). Pituitary insufficiency and diabetes insipidus requiring substitutive treatment were diagnosed following the surgery. After surgery, the patient complained of episodes of flushing on the right side of her forehead and on the nose, especially under stressful situations or following vigorous exercise, as well as sweating on the contralateral side (Figure 2). Perspiration and blood flow remained completely normal throughout the rest of her body. No gustatory or other alterations were mentioned. Thyroid, abdominal and carotid duplex ultrasonography as well as thorax conventional imaging techniques were performed without pathological findings. Internal jugular vein catheterization was not implanted before or after surgery. No other neck or upper thoracic injury was identified. 


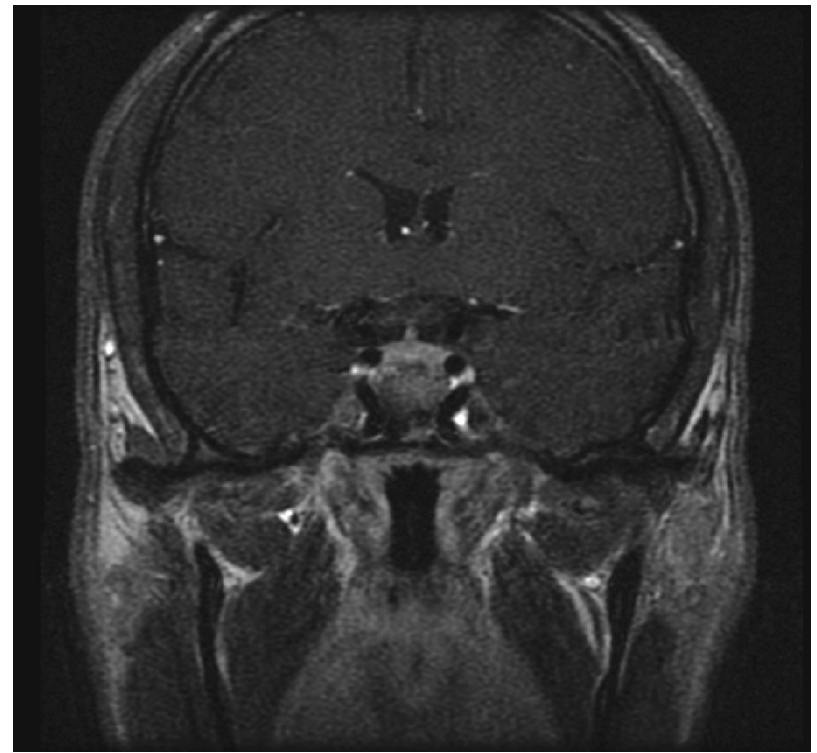

Figure 1. Preoperative coronar MRI.

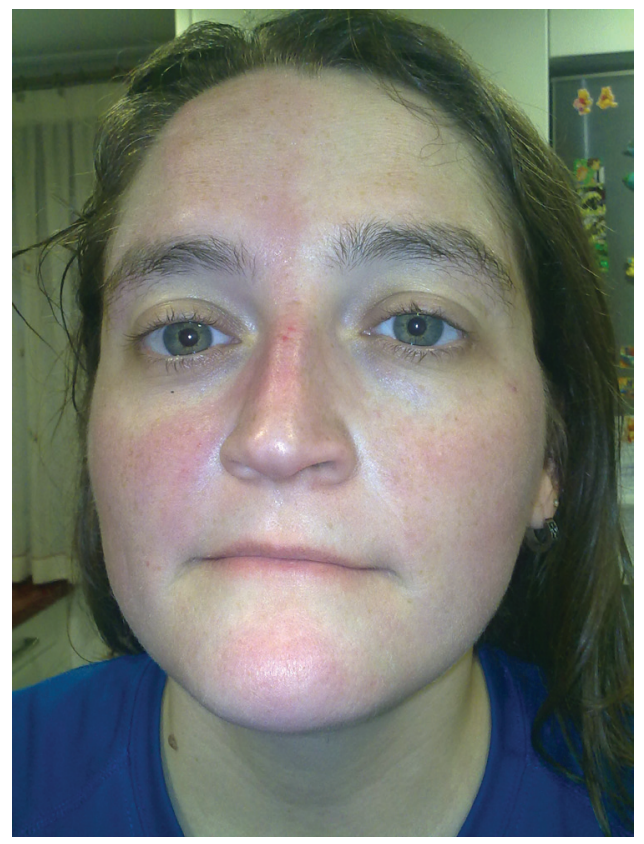

Figure 2. Loss of left-sided flushing and sweating of the face and head.

As expected, a postsurgical MRI showed an empty sella turcica without any other lesions. Neither vessel (internal carotid artery) nor main nerve bundle abnormalities (abducens, oculomotor, trochlear nerves, and ophthalmic and maxillary divisions of the trigeminal) were detected in an MRI of the cavernous sinus and the hypophysis. Furthermore, a neck MRI did not show any lesion on the common, internal or external carotid artery, spinal cord or sympathetic ganglions. No ocular signs of Horner's syndrome were detectable under careful examination and a cocaine pharmacological pupil function test. Thus, ruling out any other cause and based on the pattern of unilateral right side forehead and nose flushing and sweating reaction as well as on the postganglionic left sympathetic fibers dissection during transsphenoidal surgery, harlequin syndrome was diagnosed. The patient was informed of the benign nature of the diagnosis and she did not require any further treatment or investigations apart from the above for her panhypopituitarism.

\section{DISCUSSION}

The underlying pathophysiology of harlequin syndrome involves an ipsilateral lesion of the sympathetic vasodilator neurons innervating the face, leading to disturbed thermoregulatory vasodilatation and anhidrosis, with or without Horner's syndrome.

The sympathetic outflow pathway originates from the hypothalamus (first neurons) and synapse in the lateral horn of spinal cord (second neurons). Sudomotor and vasomotor fibers innervating the face leave the spinal cord with the ventral roots T2, T3 and travel along the sympathetic chain to the superior cervical ganglion where the synapse with the third neurons occurs. The vasomotor and sudomotor superior cervical ganglion fibers innervating the medial forehead and nose travel along the internal carotid artery forming the sympathetic plexus going through the petrous and cavernous artery segments, whereas the other facial areas (lower cheeks and chin) are supplied by fibers travelling with the external carotid artery. ${ }^{3}$ Thus, based on the pattern of symptoms in a particular case, it is relatively straightforward to identify the site of the lesion. ${ }^{4}$

In our patient, abnormal flushing reactions were limited to the right side of forehead and to the nose without affecting the chin. Such a clinical picture indicates the presence of a postganglionic lesion above the superior cervical ganglion where the sympathetic preganglionic neurons synapse with third sympathetic neurons. The lesion should hence be distal to the division of the common carotid artery due to partial 
or complete dissection of the sympathetic plexus that travels with the internal carotid artery. There are several causes of postganglionic harlequin syndrome, including internal carotid artery dissection, extracranial aneurysm of internal carotid artery, Reader's syndrome, cluster headache and transsphenoidal adenoma surgery ${ }^{5}$ resulting from partial or complete lesion of postganglionic sympathetic fibers travelling within the internal carotid artery. Their situation, next to the hypophysis in the cavernous sinus, facilitates injury during transsphenoidal surgery. ${ }^{6}$ In our case, having ruled out any other diagnosis, we concluded that postsurgical sympathetic nerve injury was the only cause that could explain the clinically apparent harlequin syndrome. It should here be noted that we were unable to document any internal carotid artery injury that could account for postganglionic sympathetic lesion. We hypothesize that post-surgical fibrosis in the left cavernous sinus may have caused the damage of the sympathetic fibers. However, we cannot exclude damage of the sympathetic nerves during the surgical procedure which was serious enough to also cause panhypopituitarism.

Because of the particularly benign nature of our patient's case, we advised her to avoid situations triggering its manifestation as the best approach. However, for patients who experience severe social embarrassment as a result of the sweating and flushing, contralateral sympathectomy has been suggested as treatment as a way of preventing the facial flushing on the normally functioning side of the face. ${ }^{7}$

\section{ACKNOWLEDGEMENTS}

We are indebted to Stewart and Irene Diaz for manuscript assistance.

\section{Declaration of interest}

The authors declare that there is no conflict of interest that would prejudice their impartiality.

\section{Funding}

This research did not receive any specific grant from any funding agency in the public, commercial or non-profit sector.

\section{REFERENCES}

1. Lance JW, Drummond PD, Gandevia SC, et al, 1988 Harlequin syndrome: the sudden onset of unilateral flushing and sweating. J Neurol Neurosurg Psychiatry 1: 635-642.

2. Pradeep PV, Benede AK, Harshita SS, Jayashree B, 2011 Harlequin syndrome in a case of toxic goitre: a rare association. Case Report Med pp 293076.

3. Duddy ME, Baker MR, 2007 Images in clinical medicine. Harlequin's darker side. N Engl J Med 357: e22.

4. Wasner G, Maag R, Ludwig J, et al, 2005 Harlequin syndrome-one face of many etiologies. Nat Clin Pract Neurol 1: 54-59.

5. Sarikaya H, Georgiadis D, Baumgartner RW, 2008 Harlequin syndrome in spontaneous dissection of the cervical carotid artery. Neurology 71: 1459.

6. Lee JH, Lee HK, Park JK, Choi CG, Suh DC, 2003 Cavernous sinus syndrome: clinical features and differential diagnosis with MR imaging. AJR Am J Roentgenol 181: 583-590.

7. Swan MC, Nicolaou M, Paes TR, 2003 Iatrogenic harlequin syndrome. Postgrad Med J 79: 278. 